\title{
Pregnancy wastage among HIV infected women in a high HIV prevalence district of India
}

\author{
Shiva S. Halli i* C.G. Hussain Khan², Iqbal Shah ${ }^{3}$, Reynold Washington ${ }^{4}$, Shajy Isac ${ }^{5}$, Stephen Moses ${ }^{6}$ \\ and James F. Blanchard ${ }^{5}$
}

\begin{abstract}
Background: Bagalkot district in Karnataka state is one of the highest HIV prevalence districts in India. A large proportion of the girls also marry at early age in the district and negative pregnancy outcomes among the HIV positive women likely to have large pregnancy wastages. Therefore, this study examined the pregnancy wastages and the associated factors among HIV positive women in a high prevalent district in India.
\end{abstract}

Methods: We used data from a cross-sectional survey conducted recently among randomly selected currently married HIV positive women, 15-29 years of age, in one of the high HIV prevalence districts in India. The study used the experience of reported pregnancy wastage as an outcome variable, and both bi-variate and multivariate logistic regression analyses were carried out to understand the factors associated with the pregnancy wastage among HIV infected women.

Results: Overall, $17 \%$ of the respondents reported pregnancy wastage, of which $81 \%$ were due to spontaneous abortions. Respondents who became pregnant since testing HIV positive reported significantly higher level of pregnancy wastage as compared to those were pregnant before they were tested for HIV. (AOR $=1.9 ; p=0.00)$. While a positive association between duration of marriage and pregnancy wastage was noticed $(A O R=7.4 ; p=0.01)$, there was a negative association between number of living children and pregnancy wastage ( $A O R=0.24 ; p=0.00)$. Living in a joint family was associated with increased reporting of pregnancy wastage as compared to those living in nuclear families ( $A O R=1.7 ; p=0.03)$.

Conclusions: HIV prevention and care programs need to consider the reproductive health needs of HIV infected married women as a priority area since large proportion of these women reported negative pregnancy outcomes. There is also a need to explore ways to raise the age at marriage in order to stop women getting married before the legal age at marriage.

Keywords: HIV, Pregnancy wastages, Abortions, Still births, Early age at marriage

\section{Background}

Globally, it is estimated that there were 35.3 million people living with HIV and 2.3 million new infections in 2012 [1]. Although the burden of the epidemic varies considerably between countries and regions, it is estimated that $0.8 \%$ of adults aged 15-49 years worldwide are living with HIV [1]. The HIV/AIDS epidemic remains a serious public health challenge, especially among women of childbearing age, who make up $46 \%$

\footnotetext{
* Correspondence: shivahalli@yahoo.com

${ }^{1}$ Centre for Global Public Health, Department of Community Health Sciences, College of Medicine, Faculty of Health Sciences, University of Manitoba, 771 McDermot Avenue, Winnipeg, Manitoba R3E OT6, Canada

Full list of author information is available at the end of the article
}

of the global HIV burden. The UNAIDS Global Report (2013) also highlights that women constitute $52 \%$ of all HIV infections in low- and middle-income countries [1]. HIV infected women are vulnerable to various reproductive health issues. Spontaneous abortion and stillbirths appear to be more common among HIV-infected women [2, 3]. In Western countries, HIV positive women, have higher rates of induced abortion [4], but it is difficult to tell whether this is also true in Asia. Medical termination of Pregnancy is legalised in India, but rural young and unmarried women frequently access unqualified practitioners who conduct abortions in unsafe settings [5]. 
Data from Zaire (now Democratic Republic of Congo) suggest that there is not much difference in induced abortions among HIV-infected women compared to non-infected in sub-Saharan Africa [6]. Evidence suggests that women presenting with spontaneous abortion had a significantly higher rate of HIV infection than those presenting for antenatal care or delivery [7]. Moreover, the same study also noted that HIV infected women had a much higher rate of recent history of fetal wastage (late abortions, neonatal deaths, premature delivery) than the non-infected group.

India is heterogeneous in socio-demographic and economic contexts with low fertility behaviours in a number of southern states as compared to northern states. Data from National Family Health Survey (NFHS-3) suggest that overall $14.4 \%$ of the ever married women ever experienced a non-live births (still births, abortions and miscarriages) [8]. The data further showed that a lower percent of 15-29 years old ever married women reported experiencing a non-live birth (10.1\%). Regional differentials were evident as far as the reported non-live birth in India with some states reporting over $20 \%$ and 7.9 \% women aged 15-49 years in Karnataka reported a non-live birth.

HIV epidemic in India is driven by heterosexual behaviours with HIV prevalence among the general population is estimated at $0.36 \%$ and an estimated people living with HIV (PLHIV) of 2.5 million in India [9].

Karnataka state in India is considered a high HIV prevalence state, with an average of $0.69 \%$ of adults aged 15-49 years estimated to be HIV positive [8]. The HIV positivity rate among the 776,185 pregnant women tested during January-December 2010 in the state was $0.36 \%$ [10]. The district of Bagalkot, in northern Karnataka, is one of the highest prevalence districts in the country, with a HIV prevalence of $2.6 \%$ among the general population in 2009, significantly higher in rural areas than urban areas [11]. Bagalkot (1.26\%), was also the only district in the state that had a HIV positivity rate of greater than $1 \%$ among pregnant women tested in 2010. The district has also reported relatively high levels of neonatal and child mortality compared to many other districts in the state [12].

Few studies attempted to understand the pregnancy outcomes among PLHIVs in India. A study conducted among Prevention of Parent to Child Transmission (PPTCT) attendees in Kadapa district of Andhra Pradesh, India found that low birth weight is an observed complication in HIV infected [13]. Further, negative pregnancy outcomes (abortions and high still births) are significantly high among HIV positive women [7, 13]. Kumar et al. [13] studied pregnancy outcomes among HIV positive women, based on a cohort of pregnant women attending HIV testing centres over a period of one year in India. Although the study recruited 4112 pregnant women, only 56 were HIV positive, so the relationship between HIV and pregnancy wastage was based on a small sample. Considering India's sociodemographic heterogeneity and differentials of negative pregnancy outcomes in the country, it is important to understand the pregnancy outcomes among PLHIV. Further, only two studies were available in the country, which discussed on pregnancy outcomes among PLHIVs using a small purposive sample. Therefore, in this paper, we examine the effect of HIV among pregnant women in a high HIV prevalent district, Bagalkot, particularly on the outcomes of abortions and still births, from a large random sample of HIV positive women.

\section{Methods}

\section{Sampling design}

The sample size for the study was decided based on $5 \%$ marginal of error and $80 \%$ power with $95 \%$ confidence level. Considering the measure of interest, namely couple protection rate of $50 \%$, the following statistical formula was used.

$$
(\mathrm{Z} 2 * \mathrm{pq}) / \mathrm{d}^{2}
$$

Using the above formula, the required sample size is 384. However, the sample was increased accounting a design effect of 1.7 as well non-response of $10 \% \mathrm{~m}$ the required sample size was around 720 .

We recruited a total of 720 young (15-29 years) HIV positive currently married women. Of the 720 participants recruited, 633 participated ( $87 \%$ response), and were administered a structured, pre-tested questionnaire in a face-to-face interview. The sample size for the study was restricted to married women, as in the context of Karnataka, childbearing is an option mainly for married women.

The Jeevan Jyothi community-based organization (CBO) in Bagalkot district is one of the earliest CBOs formed for HIV positive people in Karnataka state. The Jeevan Jyothi has established a drop-in centre (DIC) for HIV positive people in the district to access various HIV related services. Most of the (approximately 4,000) women registered with the DIC consented to be contacted, and about 2,000 were in the age group 15-29 years and were included in the sampling frame. The required sample of respondents (720) was then selected using a stratified random sampling approach, where age was considered as a stratification variable. Currently married women were stratified into 3 age groups: 15-19 years, 20-24 years and 25-29 years, and then the required number of respondents were randomly selected from each strata proportionately. 


\section{Data collection}

The field team included, 6 female interviewers and 1 supervisor. All the field investigators were at least graduates with significant field experience in collecting data. All the field team members were given one week intensive training, which included, class room lectures, orientation on questionnaire, mock interviews, visit to Jeevan Jyoti and field practices. In addition, they were trained on conducting interviews and ethics of researches. A special training was given to the supervisor in data quality control, use of monitoring tools, preparation of progress report, inter-personal communication with staff and others etc. The field work was carried out during July-August 2012.

The study used a structured interview questionnaire which was administered to each selected participant. The study questionnaire included information on fertility preferences of Women Living with HIV/AIDS, socio-economic and demographic characteristics, reproductive behaviour and contraceptive use, fertility behaviour after having HIV/AIDS, reproductive and sexual health etc.

\section{Data analysis}

The study used SPSS 22.0 statistical software, and bivariate as well as multivariate analyses were carried out. Each respondent in the survey was asked "if she ever had pregnancy that ended in still birth, spontaneous or induced abortion?". If she had experienced any, then questions were also asked how many still births, induced and spontaneous abortions. The present study included any women reported experience of still births or abortions. We compared reported pregnancy wastages among two groups of women, the group of women who became pregnant after their HIV positive status vs. the group who did not become pregnant after their HIV positive status but had pregnancies prior to HIV positive status. Multivariate logistic regression models were used to understand the correlates of reported pregnancy wastage, incorporating a set of independent variables, including place of usual residence, literacy level, occupation, age at living with current husband, duration of marriage, literacy of husband, occupation of husband, caste, type of house, type of family, monthly household income, number of living children and duration since HIV tested.

\section{Ethical considerations}

Ethical clearance was obtained from the World Health Organization's Research Ethics Review Committee, the Institutional Ethical Review Board of St John's Medical College, Bangalore, and the Health Research Ethics Board of the University of Manitoba, Winnipeg, Canada.

\section{Results}

\section{Profile of women living with HIV}

Of the 633 respondents interviewed, $27 \%$ were less than 25 years of age, with a mean age of about 26 years. Over $71 \%$ were from rural areas, about half were illiterate and $45 \%$ of the respondents' husbands were illiterate as well. Most of the respondents were Hindu (95\%), $42 \%$ belonged to scheduled castes or scheduled tribes (SC/ST); and another $28 \%$ belonged to "other backward classes" $(\mathrm{OBC})$. About $85 \%$ of respondents were engaged in labour or household work, and almost all of the respondents were currently living with their husbands and had been married only once.

Over one-fourth (28\%) of the women started living with their current husbands before the age of 15 years, and as high as $73 \%$ of respondents started living with their current husbands before the legal age of marriage of 18 years. About $83 \%$ of respondents had an age gap between respondent and husband of over 5 years. The mean age of the respondents was 25.6 years, vs. 32.5 years among their husbands, indicating a mean age gap between respondent and husband of about 7 years. Approximately $9 \%$ respondents had been married for less than 5 years, $34 \%$ and $57 \%$ respectively had been married for 5-9 years and 10+ years with median duration of marriage of 10 years. While most husbands were engaged in cultivation or manual labour, $26 \%$ worked in a business or were salaried employees.

The mean monthly household income was about Rs 7,380 (US \$120), and only one-fourth of the respondents had a monthly household income above Rs 10,000 (US \$167). Two-fifths of households (43\%) had a monthly household income between Rs 5,000 - Rs 9,999 (US \$83-167), $23 \%$ had a monthly income between Rs 3,000-Rs 4,999 (US \$50-83) and $9 \%$ had a monthly income less than Rs 3,000 (<US \$50). About $91 \%$ of respondents lived in their own house. The households were poorly maintained, with about $39 \%$ of respondents living in thatched or mud- roofed households. Over three-quarters $(79 \%)$ of respondents were living in a nuclear family, and on an average a respondent had 1.82 living children.

While about one-fourth of the respondents had recently tested HIV positive (during the past 2 years), $49 \%$ and $25 \%$ respectively were tested HIV positive $2-3$ years and $4+$ years prior to the survey, with a mean duration since testing HIV positive of 2.61 years with a standard deviation of 1.92 . Over one-third (37 \%) of the respondents had become pregnant after testing HIV positive.

\section{Levels of pregnancy wastage among WLHAs by characteristics}

The study examined the differential levels of reported pregnancy wastages by characteristics of the respondents 
and is presented in Fig. 1 and Table 1. Overall, $17 \%$ of the respondents reported ever having reported experienced pregnancy wastage, including stillbirths, induced and spontaneous abortions (Fig. 1). This included $3.8 \%$ with stillbirths, $13.7 \%$ with spontaneous abortions and $2.8 \%$ with induced abortions.

Table 1 presents the proportion of women who reported pregnancy wastage by socio-demographic characteristics. Women living with HIV reported as experienced pregnancy wastages more or less at the same level by age of the respondents, by rural and urban residence and by education status of the respondents. Those women who did not travel for work were more likely to report pregnancy wastage $(18.1 \%)$ compared to women who travelled for work $(5.3 \%$; OR $=3.97$; $\mathrm{CI}=1.22-12.93 ; \mathrm{p}=0.02)$. Younger age at living with the current husband is associated with the higher reported pregnancy wastage, $21 \%$ of the women who started living with their husbands before the age of 15 years reported a pregnancy wastage compared to $17 \%$ of women living with husbands between 15-17 years $(\mathrm{OR}=0.79 ; \mathrm{CI}=0.49-1.26 ; \mathrm{p}=0.32)$ and $11 \%$ of women living with husbands above the age of 18 years $(\mathrm{OR}=0.47$; $\mathrm{CI}=0.26-0.85 ; \mathrm{p}=0.01$ ).

Those respondents with longer than 10 years of marriage were more likely to report pregnancy wastage as compared to those married for less than 5 years $(\mathrm{OR}=$ 2.93; $\mathrm{CI}=1.02-8.38 ; \mathrm{p}=0.04$ ). While many other factors such as age gap between husband and respondent, caste, type of house and monthly household incomes were not associated with pregnancy wastage, type of family and number of living children were associated with pregnancy wastage. Those living in joint family and having fewer living children were more likely to have reported as pregnancy wastage $(\mathrm{p}<0.05)$ as compared to their counterparts. Although duration since having tested HIV positive was not significantly associated with women reporting pregnancy wastage, those who became pregnant since testing HIV positive were significantly more likely to report pregnancy wastage $(\mathrm{OR}=1.64$; $\mathrm{CI}=1.08-2.50 ; \mathrm{p}=0.02$ ).

\section{Associated factors of reported pregnancy wastage}

Multivariate logistics model was used to understand the determinants of reported pregnancy wastages. The adjusted odds ratios and $\mathrm{P}$ values are presented in Table 2 only for the variables which were significant $(\mathrm{P}<0.05)$ in bivariate models. Duration of marriage, type of family, number of living children, and whether pregnant since testing HIV positive, were all associated with reported pregnancy wastage. Women who became pregnant after testing HIV positive had almost double the risk of reporting pregnancy wastage $(\mathrm{AOR}=1.96 ; \mathrm{CI}=1.2-3.2$; $\mathrm{p}=0.00$ ) even after controlling other variables. Increased duration of marriage increased the risk of reporting pregnancy wastage. A woman with 5-9 years duration of marriage had an increased reporting of pregnancy wastage as compared to women with less than 5 years of duration of marriage ( $\mathrm{AOR}=4.23 ; \mathrm{CI}=1.16-15.45 ; \mathrm{p}=0.02)$. Similarly, women having $10+$ years of duration of marriage had further increased risk as compared to women with less than 5 years of marriage duration $(\mathrm{AOR}=7.45$; $\mathrm{CI}=1.46-38.03 ; \mathrm{p}=0.01$.

Type of family was associated with reported pregnancy wastage. HIV positive women in a joint family were more likely to report pregnancy wastage compared to those women in a nuclear family (AOR $=1.77$; $\mathrm{CI}=1.04$ 3.05; $\mathrm{p}=0.03$ ). Women with higher numbers of living children $(3+$ children) were less likely to report pregnancy wastage, compared to women with no living children $(\mathrm{AOR}=0.24 ; \mathrm{CI}=0.11-0.53 ; \mathrm{p}=0.00)$.

\section{Discussion}

DLHS (IIPS, 2007-08) showed that in the state of Karnataka and in Bagalkot district, about $4 \%$ of all pregnancies among the general population resulted in



Fig. 1 Percent HIV positive women experienced pregnancy wastages 
Table 1 Percent of HIV positive women experiencing of pregnancy wastage by characteristics

\begin{tabular}{|c|c|c|c|c|c|c|c|}
\hline \multirow[t]{2}{*}{ Characteristics } & & \multirow[t]{2}{*}{ Number } & \multirow{2}{*}{$\begin{array}{l}\% \text { ever had still } \\
\text { birth or abortions }\end{array}$} & \multirow[t]{2}{*}{ Odds Ratio } & \multicolumn{2}{|c|}{$95 \%$ Confidence Interval } & \multirow[t]{2}{*}{$p$} \\
\hline & & & & & Lower & Upper & \\
\hline Total & & 633 & 16.9 & & & & \\
\hline \multirow[t]{2}{*}{ Age } & $<25$ years & 168 & 18.5 & 1.00 & & & \\
\hline & $25+$ years & 465 & 16.3 & 0.86 & 0.54 & 1.37 & 0.53 \\
\hline \multirow[t]{2}{*}{ Place of usual residence } & Urban & 179 & 16.2 & 1.00 & & & \\
\hline & Rural & 454 & 17.2 & 1.07 & 0.67 & 1.71 & 0.77 \\
\hline \multirow[t]{2}{*}{ Literacy level } & Literate & 327 & 16.5 & 1.00 & & & \\
\hline & Illiterate & 306 & 17.3 & 1.06 & 0.70 & 1.61 & 0.79 \\
\hline \multirow[t]{4}{*}{ Occupation } & Cultivator & 50 & 18.0 & 1.00 & & & \\
\hline & Labour & 259 & 17.8 & 0.98 & 0.45 & 2.16 & 0.97 \\
\hline & Household work & 279 & 16.5 & 0.90 & 0.41 & 1.98 & 0.79 \\
\hline & Others & 45 & 13.3 & 0.70 & 0.23 & 2.15 & 0.53 \\
\hline \multirow[t]{2}{*}{ Travel due to work } & Yes & 57 & 5.3 & 1.00 & & & \\
\hline & No & 576 & 18.1 & 3.97 & 1.22 & 12.93 & 0.02 \\
\hline \multirow{3}{*}{$\begin{array}{l}\text { Age at living with current } \\
\text { husband }\end{array}$} & $<15$ years & 175 & 21.1 & 1.00 & & & \\
\hline & $15-17$ years & 287 & 17.4 & 0.78 & 0.49 & 1.26 & 0.32 \\
\hline & $18+$ years & 170 & 11.2 & 0.46 & 0.26 & 0.85 & 0.01 \\
\hline \multirow[t]{3}{*}{ Durations of marriage } & $<5$ years & 57 & 7.0 & 1.00 & & & \\
\hline & $5-9$ years & 216 & 17.1 & 2.74 & 0.93 & 8.03 & 0.07 \\
\hline & $10+$ years & 359 & 18.1 & 2.93 & 1.02 & 8.38 & 0.05 \\
\hline \multirow[t]{2}{*}{ Literacy of husband } & Literate & 348 & 15.2 & 1.00 & & & \\
\hline & Illiterate & 285 & 18.9 & 1.30 & 0.86 & 1.97 & 0.22 \\
\hline \multirow[t]{4}{*}{ Occupation of husband } & Cultivator & 191 & 16.2 & 1.00 & & & \\
\hline & Labour & 251 & 17.9 & 1.13 & 0.68 & 1.86 & 0.64 \\
\hline & Business/Salaried & 167 & 14.4 & 0.87 & 0.49 & 1.55 & 0.63 \\
\hline & Others & 24 & 29.2 & 2.13 & 0.81 & 5.55 & 0.12 \\
\hline \multirow[t]{3}{*}{ Caste } & SC/ST & 267 & 15.4 & 1.00 & & & \\
\hline & $\mathrm{OBC}$ & 177 & 19.8 & 1.36 & 0.83 & 2.23 & 0.23 \\
\hline & Others & 189 & 16.4 & 1.08 & 0.65 & 1.80 & 0.76 \\
\hline \multirow[t]{2}{*}{ Type of house } & Thatched/mud roof & 248 & 19.8 & 1.00 & & & \\
\hline & Others & 385 & 15.1 & 0.72 & 0.47 & 1.10 & 0.13 \\
\hline \multirow[t]{4}{*}{ Monthly HH income } & $<$ Rs 3000 & 58 & 24.1 & 1.00 & & & \\
\hline & Rs 3000-4999 & 145 & 20.0 & 0.79 & 0.38 & 1.62 & 0.52 \\
\hline & Rs 5000-9999 & 275 & 14.9 & 0.55 & 0.28 & 1.09 & 0.09 \\
\hline & Rs $10000+$ & 155 & 14.8 & 0.55 & 0.26 & 1.16 & 0.11 \\
\hline \multirow[t]{2}{*}{ Type of family } & Nuclear & 497 & 15.3 & 1.00 & & & \\
\hline & Others & 136 & 22.8 & 1.64 & 1.02 & 2.61 & 0.04 \\
\hline \multirow[t]{3}{*}{ Total number of living children } & 0 & 92 & 23.9 & 1.00 & & & \\
\hline & $1-2$ & 366 & 17.5 & 0.67 & 0.39 & 1.17 & 0.16 \\
\hline & $3+$ & 175 & 12.0 & 0.43 & 0.22 & 0.84 & 0.01 \\
\hline \multirow[t]{3}{*}{ Duration since tested HIV-years } & $<2$ year & 165 & 15.2 & 1.00 & & & \\
\hline & $2-3$ years & 311 & 18.0 & 1.23 & 0.74 & 2.06 & 0.43 \\
\hline & $4+$ years & 157 & 16.6 & 1.11 & 0.61 & 2.02 & 0.73 \\
\hline
\end{tabular}


Table 1 Percent of HIV positive women experiencing of pregnancy wastage by characteristics (Continued)

\begin{tabular}{lllllll}
\hline Pregnant since tested positive & No & 400 & 14.3 & 1.00 & & \\
& & & 21.5 & & & \\
& Yes & 233 & & 1.64 & 1.08 & 2.50 \\
\hline
\end{tabular}

spontaneous abortions. However, our study showed that as high as $14 \%$ of our sample of currently married HIV infected women had ever reported experiencing spontaneous abortions, and about $4 \%$ had reported experiencing stillbirths, indicating a very high level of pregnancy wastage. The most conspicuous finding of the study is that the women who became pregnant since testing HIV positive had an increased risk of reporting pregnancy wastage. Gray et al. [2] demonstrated that spontaneous abortion is more common in HIV infected women in Uganda. Similarly, in a meta-analysis [3], the association between HIV positivity and the risk of spontaneous abortion ranged from 1.8 to 6 fold. Similarly, the association between HIV infection and increased risk of delivering low birth weight infants was studied in Tanzania [14], and associations between HIV infection and low birth weight, preterm delivery and intrauterine growth retardation were found. Gray et al. [2] and Brocklehurst and French [3] also showed that miscarriages, spontaneous abortions and stillbirths were more common in HIV infected women. A study to examine the effect of HIV infection on pregnancy wastage in Dar es Salaam, Tanzania [7] found that women presenting with spontaneous abortions had a significantly higher rate of HIV infection than those presenting for antenatal care or delivery, and that the HIV infected group had a much higher rate of recent history of fetal wastage (late abortions, neonatal deaths, premature delivery) than the non-infected group. In addition, HIV infected women delivered lower birth weight babies than the noninfected women [13].

Another important factor that is positively associated with the increased pregnancy wastage among HIV infected women is the duration of marriage. A large proportion of the respondents are married at a very young age with large age gap between the husband and the respondent. They are likely to be infected by their husbands, who engage in pre-marital as well as extra marital sexual encounters with female sex workers, which are quite common in the study area [15]. There is also sufficient evidence to show that HIV infected women tend to suffer from sexually transmitted infections (STIs), especially syphilis and in turn leading to spontaneous abortions [16]. Sexually transmissible diseases and medical complications were diagnosed almost twice as often among sero-positive women [17]. After controlling for factors such as sexually transmissible diseases, Leroy et al. [18], observed a significant increase in adverse obstetrical events, such as maternal postpartum haemorrhage and postoperative endometritis, as also confirmed by other authors [19].

The surprising finding is that the infected women living in joint families reported experiencing higher risk of pregnancy wastage. Stigma and discrimination from family members including parents and parents-in-law could be a probable reason as those experiencing stigma and discrimination are much less likely to receive care and support. Although the results are not presented here, $88 \%$ of the women in our sample reported experiencing stigma and discrimination. Those experiencing stigma and discrimination are much less likely to access care and support as shown in a study in Vietnam, $60 \%$ pregnant women refused HIV testing cited fear and discrimination as the dominant reason [20]. Both experiences of stigma and fears of stigma can have negative effects on health behavior and health outcomes. Stigma has been shown to be associated with psychological distress and with negative health outcomes [21], and has also been shown as a substantial barrier to uptake of HIV testing and other health services [22, 23, 24].

Most married women in India opt for tubectomy (female sterilization) within 3-5 years of marriage with one or more living children [25]. The longer duration of marriage, associated with increased reports of pregnancy wastage is indicative of poor access to permanent methods of contraception. The study shows that $6 \%$ of the respondents are contributing to $62 \%$ of the pregnancy wastage indicating multiple pregnancy wastages among a fewer number of women.

\section{Conclusion and implications}

Those who were pregnant since testing HIV positive had about double the risk of reporting pregnancy wastage even after controlling the effect of other variables. As argued in the discussion, the prevalence of STIs among these women requires regular screening for STIs. In addition to this, high level of unmet need for family planning due to poor access to permanent (terminal) methods because of their HIV status, special attention needed for HIV infected women to provide spacing and permanent methods of contraceptive services. Similarly, to reduce stigma and discrimination, interventions including counselling, especially to the family members need to be introduced. A large proportion of the girls in the district continue to get married before the legal age at marriage, culturally appropriate communication 
Table 2 Unadjusted and adjusted odd ratios of factors associated with pregnancy wastage

\begin{tabular}{|c|c|c|c|c|c|c|c|c|c|}
\hline & & \multicolumn{4}{|l|}{ Unadjusted } & \multicolumn{4}{|l|}{ Adjusted } \\
\hline & & \multirow[t]{2}{*}{ Odds Ratio } & \multicolumn{2}{|c|}{$95 \%$ C.I. for Odds Ratio } & \multirow[t]{2}{*}{ P } & \multirow[t]{2}{*}{ Odds Ratio } & \multicolumn{2}{|c|}{95 \% C.I. for Odds Ratio } & \multirow[t]{2}{*}{$P$} \\
\hline & & & Lower & Upper & & & Lower & Upper & \\
\hline \multirow[t]{2}{*}{ Travel due to work } & No & 1.00 & & & & 1.00 & & & \\
\hline & Yes & 0.25 & 0.07 & 0.82 & 0.02 & 0.30 & 0.08 & 1.09 & 0.06 \\
\hline \multirow[t]{3}{*}{ Age at living with husband } & $<15$ & 1.00 & & & & 1.00 & & & \\
\hline & $15-17$ & 0.78 & 0.49 & 1.26 & 0.32 & 0.85 & 0.50 & 1.45 & 0.56 \\
\hline & $18+$ & 0.46 & 0.25 & 0.85 & 0.01 & 0.72 & 0.29 & 1.77 & 0.48 \\
\hline \multirow[t]{3}{*}{ Age gap between husband and respondent } & $<5$ & 1.00 & & & & 1.00 & & & \\
\hline & $5-9$ & 1.30 & 0.70 & 2.42 & 0.39 & 1.36 & 0.65 & 2.82 & 0.40 \\
\hline & $10+$ & 2.08 & 0.99 & 4.35 & 0.05 & 2.15 & 0.75 & 6.11 & 0.14 \\
\hline \multirow[t]{3}{*}{ Duration of marriage } & $<5$ & 1.00 & & & & 1.00 & & & \\
\hline & $5-9$ & 2.73 & 0.93 & 8.03 & 0.06 & 4.23 & 1.15 & 15.46 & 0.02 \\
\hline & $10+$ & 2.92 & 1.02 & 8.38 & 0.04 & 7.45 & 1.46 & 38.03 & 0.01 \\
\hline \multirow[t]{2}{*}{ Type of family } & Nuclear & 1.00 & & & & 1.00 & & & \\
\hline & Other & 1.63 & 1.02 & 2.61 & 0.04 & 1.77 & 1.03 & 3.04 & 0.03 \\
\hline \multirow[t]{3}{*}{ Number of living children } & 0 & 1.00 & & & & 1.00 & & & \\
\hline & $1-2$ & 0.67 & 0.38 & 1.16 & 0.16 & 0.37 & 0.19 & 0.71 & 0.00 \\
\hline & $3+$ & 0.43 & 0.22 & 0.84 & 0.01 & 0.24 & 0.11 & 0.53 & 0.00 \\
\hline \multirow[t]{2}{*}{ Pregnant since tested HIV } & No & 1.00 & & & & 1.00 & & & \\
\hline & Yes & 1.64 & 1.08 & 2.50 & 0.02 & 1.96 & 1.20 & 3.20 & 0.00 \\
\hline \multirow[t]{2}{*}{ Had history of child death } & No & 1.00 & & & & 1.00 & & & \\
\hline & Yes & 1.62 & 1.04 & 2.53 & 0.03 & 1.33 & 0.80 & 2.20 & 0.25 \\
\hline
\end{tabular}


programs that target unmarried adolescent girls and the people who influence the decisions should be introduced to increase womens' age at marriage. Moreover, those girls who get married at younger ages are usually infected by their husbands who engage in pre and extramarital sex with the female sex workers [14], and therefore, the programs needs to promote safe sex practices especially among the youth. Parents should also encourage HIV testing for their children before marriage.

\section{Limitations of the study}

This study recruited a large sample of young women living with HIV, usually seen as a difficult population to interview. Since all or most of the PLHIVs in the district are registered with the community organization, Chaitanya Mahila Sangha, the sample of participants selected largely represent the young HIV infected women in the Bagalkot district. The study addressed an important reproductive aspect of pregnancy loss among a highly vulnerable and stigmatized population in a high HIV prevalent district in India. While this study has shown some very important findings, there are certain limitations.

- The study is a cross sectional and hence the profile of study participants refers to the time of survey instead of the profile at the time of pregnancy wastage occurred.

- This is not a randomized control trial and hence the risk of pregnancy wastage due to HIV positive status could have been different.

- Another limitation of the study could be associated with the sampling frame. As indicated by the HIV positive network, we believe that the sampling frame is complete. In case some HIV positive women register outside the district as a result of stigma and discrimination, then there could be bias in the outcome as a result of incomplete sampling frame.

\section{Abbreviations}

HIV: Human Immuno Virus; AIDS: Acquired Immume Deficiency Syndrome; OR: Odds Ratio; AOR: Adjusted Odds Ratio; Cl: Confidence Interval; STI: Sexually Transmitted Infection; CBO: Community Based Organization; SC/ST: Scheduled Tribe/Scheduled Caste; OBC: Other Backward Class; DIC+: Drop in center +; PPTCT: Prevention of parent to child transmission.

\section{Competing interests}

All authors declare that they have no competing interests.

\section{Authors' contributions}

$\mathrm{SH}$ contributed to the design of the study and the survey materials, was involved in data collection, conducted the data analysis and drafted the manuscript. HK, IS and RW contributed to the design of the study and survey materials and contributed to the data interpretation and review of the manuscript. SI was involved in data analysis, interpretation and drafting of the manuscript. SM and JB was involved in the design of the study, development of survey materials, data interpretation and review of the manuscript. All authors read and approved the final manuscript.

\section{Acknowledgments}

The authors wish to thank the Jeevan Jyothi DIC+ and its members for their support and participation in the study. Thanks are also due to the World Health Organisation for funding the project from which the data is used. Special thanks to Dr. Lale Say and Dr. Rita Karba of WHO for their support.

\section{Author details}

${ }^{1}$ Centre for Global Public Health, Department of Community Health Sciences, College of Medicine, Faculty of Health Sciences, University of Manitoba, 771 McDermot Avenue, Winnipeg, Manitoba R3E 0T6, Canada. 'Department of Anthropology, Karnataka University, Dharwad, Karnataka 586003, India. ${ }^{3}$ Chemin de Malvand, Chambesy 12C 1292, Switzerland. ${ }^{4}$ Karnataka Health Promotion Trust, 1-4, IT Park, 5th Floor, Rajajinagar Industrial Area, Bangalore, Rajajinagar 560044, India. ${ }^{5}$ Centre for Global Public Health, Department of Community Health Sciences, College of Medicine, Faculty of Health Sciences, University of Manitoba, 771 McDermot Avenue, Winnipeg, Manitoba R3E 0T6, Canada. ${ }^{6}$ Department of Community Health Sciences, College of Medicine, Faculty of Health Sciences, University of Manitoba, 771 McDermot Avenue, Winnipeg, Manitoba R3E OT6, Canada.

Received: 13 March 2014 Accepted: 24 June 2015

Published online: 02 July 2015

\section{References}

1. UNAIDS. Global Report. Geneva: UNAIDS report on the global AIDS epidemic; 2013.

2. Gray RH, Wawer MJ, Serwadda D, Sewankambo N, Li C, Wabwire-Mangen F, et al. Population-based study of fertility in women with HIV-1 infection in Uganda. Lancet. 1998;351(9096):98-103.

3. Brocklehurst P, French R. The association between maternal HIV infection and perinatal outcome: a systematic review of the literature and meta-analysis. BJOG. 1998;105:836-48.

4. Stephenson JM, Griffioen A. Study group for the medical research council collaborative study: The effect of HIV diagnosis on reproductive experience. AIDS. 1996;10:1683-7.

5. Varkey P, Balakrishna PP, Prsad JH, Abraham H, Joseph A. The reality of unsafe abortion in a rural community in south India. Reprod Health Matters. 2000;8(16):83-91.

6. Ryder RW, Batter VL, Nsuami M, Badi N, Mundele L, Matale B, et al. Fertility rates in $238 \mathrm{HIV}$-1-seropositive women in Zaire followed for 3 years post-partum. AIDS. 1991;5(12):1521-7.

7. Urass EJ, Kilewo C, Mtavangu R, Mhalu FS, Mbena E, Biberfeld G. The role of HIV infection in pregnancy wastage in Dar e Salaam, Tanzania. J of Obst and Gynaec of Eastern and Central Africa. 1992;10:70-2.

8. National Family Health Survey 3 (NFHS-3). International Institute for Population Sciences (IIPS) and Macro International. Ith ed. Mumbai, India: National Family Health Survey (NFHS-3), 2005-2006: India; 2007.

9. Arvind P, Dandu CS R, Ghys PD, Mariamma T, Damodar S, Madhulekha B, et al. Improved estimates of India's HIV burden in 2006. Indian J Med Res. 2009;129:50-8.

10. Karnataka State AIDS Prevention Society (KSAPS). Management Information System. Bangalore, India: Karnataka State AIDS Prevention Society (KSAPS); 2010.

11. General Population Survey (GPS). HIV and STIs in Bagalkot district. Karnataka, India: A general population survey, CHARME working paper; 2009.

12. Usha R, Prabhat Jha, Ram F, Kumar K, Awasthi S, Shet A, Pader J, Nansukusa S, Kumar R. Neonatal, 1-59 month, and under-5 mortality in 597 Indian districts, 2001 to 2012, estimates from national demographic and mortality surveys. The Lancet Global Health. 2013;1(4):e219-e226. http://www.thelancet.com/journals/ langlo/article/PIIS2214-109X(13)70073-1/fulltext.

13. Kishore Kumar KJ, Seran Kumar RM, Chandra SK, Sujit Kumar DS, Bala KC. A profile of HIV positive antenatal women at PPTCT centre, Kadapa. Indian J of Public Health Research \& Development. 2011;2(1):24-26.

14. Dreyfuss ML, Msamanga GI, Spiegelman D, Hunter DJ, Urassa EJN,

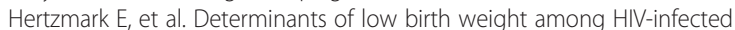
pregnant women in Tanzania. Am J Clin Nutr. 2001;74:814-26.

15. Blanchard, James F., Halli S, Ramesh BM, Bhattacharjee P, Washington RG, O'Neil J, Moses S. Variability in the sexual structure in a rural Indian setting: Implications for HIV prevention strategies, Sex Transm Infect., 2007;83(Suppl 1):i30-i36P. 
16. Miotti, PG, Gina D, Eric N, George L, Alfred JS. HIV-1 and pregnant women: associated factors, prevalence, estimate of incidence and role in fetal wastage in central Africa. AIDS. 1990;4(8):733-6.

17. Ryder RW, Nsa W, Hassia SE, et al. Prenatal transmission of the human immunodeficiency virus type 1 to infants of seropositive women in Zaire. N Engl J Med. 1989;320:1837-42.

18. Leroy $V$, Ladner J, Nyiraziraje M, et al. Effect of HIV-1 infection on pregnancy outcome in women in Kigali, Rwanda, 1992-1994. AIDS. 1998;12:643-50.

19. Urbani G, De Vries MM, Cronje HS, et al. Complications assoiated with cesarean section in HIV-infected patients. Int J Gynaecol Obstet. 2001;74:9-15.

20. Nguyen TA, Oosterhoff $P$, Ngoc YP, Write $P$, Hardon A. Barriers to access prevention of mother-to-child transmission for HIV positive women in a well-resourced setting in Vietnam. AIDS Res Ther. 2008;5:7.

21. Quinn DM, Chaudoir SR. Living with a concealable stigmatized identity: the impact of anticipated stigma, centrality, salience, and cultural stigma on psychological distress and health. J Pers Soc Psychol. 2009;97(4):634-51.

22. Kalichman SC, Simbayi LC. HIV testing attitudes, AIDS stigma, and voluntary HIV counselling and testing in a black township in Cape Town, South Africa. Sex Transm Infect. 2003;79(6):442-7.

23. Meiberg $A E$, Bos $A E$, Onya $H E$, Schaalma HP. Fear of stigmatization as barrier to voluntary HIV counselling and testing in South Africa. East Afr J Public Health. 2008:5(2):49-54.

24. Turan JM, Bukusi EA, Onono M, Holzemer WL, Miller S, Cohen CR. HIV/AIDS stigma and refusal of HIV testing among pregnant women in rural Kenya: results from the MAMAS Study. AIDS Behav. 2011;15(6):1111-20.

25. Vlassoff, C. Progress and Stagnation, Changes in Fertility and Women's Position in an Indian Village, Population Studies: A Journal of Demography. 1992:46(2):733-6.

\section{Submit your next manuscript to BioMed Central and take full advantage of:}

- Convenient online submission

- Thorough peer review

- No space constraints or color figure charges

- Immediate publication on acceptance

- Inclusion in PubMed, CAS, Scopus and Google Scholar

- Research which is freely available for redistribution 